\title{
LA INTERVENCION MUNICIPAL EN LA INSTALACION DE PUERTOS DEPORTIVOS
}

$352: 627.2$

por

Nemesio Rodríguez Moro

Ha sido frecuente, desde hace muchos años, el planteamiento de situaciones conflictivas entre las autoridades de los Ministerios de Obras Públicas y Marina y los Ayuntamientos en relación con las respectivas competencias dentro de la zona marítimo-terrestre. Sin remontarnos a fechas muy lejanas, podemos referirnos al conflicto surgido entre los Ministerios de la Gobernación y Fomento a consecuencia de haber pretendido el Ayuntamiento de Valencia exaccionar determinados arbitrios municipales en el puerto y sus muelles, oponiéndose el Director de la Junta de Obras del Puerto, asunto que se resolvió por Decreto de 31 de marzo de 1914 en favor del Ministerio de la Gobernación.

Las causas que han dado lugar a estas situaciones conflictivas son muy varias, pero fundamentalmente se deben a una falta de comprensión de los límites de las competencias atribuidas por el legislador a los diversos organismos, y en este sentido la jurisprudencia del Tribunal Supremo ha venido repitiendo que las competencias que se pueden ejercer por los organismos estatales y los Ayuntamientos en la zona marítimo-terrestre son competencias concurrentes, y es, por tanto, necesario procurar una coordinación en la actuación de aquéllos con objeto de que los fines públicos que a cada uno de ellos le haya asignado el legislador puedan cumplirse del modo más eficaz posible. Ya la Ley de Costas de 1969 vino a reconocer con claridad una intervención importante de los Ayuntamientos en la zona marítimo-terrestre, y la Ley del Suelo de 12 de 
mayo de 1956 impuso el sometimiento a la norma urbanística no sólo de las actividades de los particulares, sino también de los organismos de la Administración pública en general, sometimiento que ha sido aún reforzado en el nuevo texto de 9 de abril de 1976. Y así, después de disponer en su artículo $10^{\circ}$ que «es objeto de la presente Ley la ordenación urbanística en todo el territorio nacional», establece en su artículo 179 que la competencia para otorgar las licencias corresponde, con carácter general, a los Ayuntamientos. $\mathrm{Y}$ el artículo 180 dispone que los actos relacionados en el artículo 178 que se promovieren por parte de órganos del Estado. - Entidades de Derecho público que administren bienes estatales. estarán igualmente sujetos a licencia municipal, y sólo en casos en que se trate de situaciones de urgencia o excepcional interés público resolverá el Consejo de Ministros mediante el trámite que en dicho artículo se establece.

Hechas estas someras indicaciones de carácter general, nos referiremos a la sentencia del Tribunal Supremo de 18 de mayo de 1984 (Aranzadi 2905), en la que ha sido ponente el Magistrado excelentísimo señor don José Luis Ruiz Sánchez, y cuyos hechos, en extracto, son los siguientes:

1. El Consejo de Ministros, por su acuerdo de 26 de octubre de 1979, otorgó concesión para construir un puerto deportivo en la Albufereta, término municipal de Alicante. La ubicación era en otro lugar distinto al previsto en el Plan de Ordenación Urbana.

Entre las condiciones que al efecto se establecían en el pliego de condiciones para la concesión parece oportuno destacar las siguientes:

a) La duración sería por cincuenta años.

b) Las obras habrían de acomodarse al proyecto técnico aprobado, debiendo terminarlas en el plazo de tres años.

c) Se fijan en 24.100 metros cuadrados los que se hayan de ganar al mar por las obras del puerto.

d) El paseo marítimo será público y gratuito.

2. Contra el acuerdo del Consejo de Ministros que otorgó la concesión interpuso el Ayuntamiento de Alicante el oportuno recurso de reposición, que fue desestimado, y después el recurso contencioso-administrativo ante el Tribunal Supremo, el cual resolvió la cuestión por la sentencia arriba citada. 
El Ayuntamiento adujo como razones fundamentales de su recurso las siguientes:

A) Que la zona marítimo-terrestre se halla sometida a la normativa urbanística, como parte que es del término municipal.

B) Que existe una clara invasión de la competencia urbanística propia del Plan de Ordenación, que supone quebranto de la Ley del Suelo en su Texto Refundido de 9 de abril de 1976, en sus artículos 10,$1 ; 12,1, a)$, y 17,1 , en relación con el $\left.6 .^{\circ} ; 19,1, a\right)$, y 76,6 , del Reglamento de Planeamiento, aprobado por Real Decreto 2159/ 1978, de 23 de junio, y artículo 15, 1, de éste.

C) Que el acuerdo del Consejo de Ministros impugnado infringe determinaciones expresas del Plan General de Ordenación Urbana de Alicante, ya que siendo objeto de previsión en el mismo un puerto deportivo, se prescinde de un modo total y absoluto del consignado en dicho Plan, no sólo en sus características, ubicación y demás especificaciones establecidas, con clara transgresión de lo previsto en los artículos 57 y 58 del Texto Refundido de la Ley del Suelo en cuanto a la efectividad y eficacia de los Planes.

D) Que es esta una materia en la que se produce la concurrencia de competencias municipales con las del Ministerio de Obras Públicas, y por ello, con independencia de las concretas normas que sean establecidas para que el puerto deportivo cumpla su función, deben tenerse presentes las normas de carácter urbanístico y al Ayuntamiento corresponde que sean cumplidas.

Por su parte, la línea argumental en que se basa la sentencia del Tribunal Supremo objeto de este comentario puede sintetizarse en los siguientes puntos:

Primero.-Que en la zona marítimo-terrestre, que forma parte del territorio municipal correspondiente, rige la norma urbanística, que tanto en cuanto al planeamiento como en cuanto a ejecución de la ordenación urbanística corresponde a la competencia municipal, y, por tanto, ha de rechazarse todo intento de desapoderar a los Municipios de las competencias urbanísticas en las zonas marítimo-terrestres, playas y zonas portuarias, tanto en cuanto a la intervención singular por vía de licencia, como en punto a la ordenación urbanística. Es decir, en suma, se insiste en que la ordenación y la ejecución urbanística es competencia exclusiva que a los Ayuntamientos corresponde en las precitadas zonas, como, en general, en el territorio que pertenece a los términos municipales de aquéllos. 
Segundo.-Que la concurrencia de competencias que se produce en la zona marítimo-terrestre ha de desenvolverse en una coordinación tal que permita llevar a cabo del mejor modo posible los fines específicos que a cada organismo público le ha asignado el legislador, teniendo muy en cuenta que las Leyes tienen el mismo valor y no puede infravalorarse la normativa urbanística. La consecución de los fines perseguidos por el puerto deportivo han de obtenerse teniendo en cuenta las disposiciones establecidas en la normativa urbanística que pueda afectarle, materia ésta que es de la competencia municipal, pues «ninguna otra disposición de jerarquía normativa suficiente limita la competencia municipal urbanística, referida tanto a la ordenación como a la ejecución». De manera que todas las concretas especificaciones técnicas que pueda establecer el Ministerio en orden a mejor conseguir los fines perseguidos con la instalación de que se trate (en este caso, el puerto deportivo) «tienen que ajustarse y acoplarse, para su cabal integración, en las previsiones urbanísticas, como medio para alcanzar la estabilidad y armonía del todo urbano".

Este es un punto en el que insiste una y otra vez la sentencia mencionada, queriendo dejar bien claro que las competencias, que son irrenunciables, cuando se producen en concurrencia en determinado territorio han de coordinarse de tal manera que cada organismo ejerza la suya para conseguir los fines públicos que la Ley le fija, pero sin inmiscuirse en el campo competencial del otro organismo concurrente. $Y$ así dice en otro considerando que "son cuestiones distintas las previsiones de carácter técnico exigibles por la legislación típica - puertos deportivos - y las características que suelen reunir las edificaciones e instalaciones para su conformación a lo planeado como exigencias urbanas del término municipal».

Tercero.-Que es una infracción del planeamiento urbanístico vigente en Alicante la instalación del puerto deportivo de que se trata en lugar distinto al que ya se había previsto en el Plan de Urbanismo, sin que haya habido razones que motiven tal cambio ni se haya producido una modificación de dicho Plan, el cual, en tanto esté vigente, no puede por menos de aplicarse, sin que pueda aceptarse una prevalencia en la actuación de otro organismo público frente al Ayuntamiento encargado de velar por el cumplimiento de la norma urbanística, pues en las concurrencias concurrentes en una materia "no hay prevalencia por el rango de los organismos intervinientes, sino por la naturaleza de las atribuciones que les han sido 
conferidas por el ordenamiento jurídico como derivación de la concepción del 'Estado social y democrático de Derecho' que se establece en el artículo 1, 1, de la Constitución».

Como consecuencia de tales razonamientos, el Tribunal estimó el recurso interpuesto por el Ayuntamiento de Alicante contra el acuerdo del Consejo de Ministros de 26 de octubre de 1979, acuerdo que el Tribunal anula por no estar ajustado a Derecho.

Estimamos que esta sentencia viene a dejar claro el tema de las concurrencias competentes en la zona marítimo-terrestre, materia que ha venido siendo objeto de gran controversia, si bien en los últimos años la jurisprudencia ha venido manteniendo una línea bastante clara en esta materia.

Si se quiere conocer con más amplitud el tema, pueden verse, entre otros, los trabajos publicados en la Revista de Administración Pública, número 51, «La licencia municipal de construcción en las zonas marítimo-terrestre y portuaria», de Isidoro GoNZÁlEZ RoDRfGUEZ, y número 52, "Las diversas competencias que concurren en la zona marítimo-terrestre», de Nemesio Rodrf́guez Moro.

Para que mejor pueda apreciarse en sus detalles y pormenores el razonamiento del Tribunal Supremo, se transcriben íntegramente los considerandos que se han estimado de mayor interés. Dicen así:

CONSIDERANDo: Que la complejidad de la cuestión planteada exige el examen de la temática derivada de la naturaleza de los bienes afectados, en función y relación con la normativa en juego, conjugando y valorando su orden prioritario con la obligada valoración de las competencias concurrentes, puesto que no puede aceptarse el criterio simplista propugnado por la parte coadyuvante, quien estima que la actuación preferente e incluso excluyente radica en la conceptuación del terreno afectado, bien como zona marítimo-terrestre y playa, o bien mar territorial, su lecho y subsuelo, de modo que en uno $u$ otro supuesto la actuación comportará exclusión de actividad compartida con una sumisión secundaria a la planificación urbana, lo que supone que se prescindiría del presupuesto esencial de la clasificación del suelo y demás condicionamientos urbanísticos, por ello hemos de partir del artículo 132, 2, de la Constitución, que expresamente dispone que «son bienes de dominio público estatal los que determine la Ley y, en todo caso, la zona marítimo-terrestre, las playas, el mar territorial y los recursos naturales de la zona económica y la plataforma continentalı, describiéndose en el ordenamiento correspondiente, de modo conceptual; puro sin alteración de genus -dominio público- las distintas especies, como concretamente en la materia que nos interesa, en el artículo $1 .^{\circ}$ de la Ley 28/1969, de 26 de abril, 
sobre Costas, en relación con el $10^{\circ}$ del Real Decreto-ley de 19 de enero de 1928, de Puertos, y el Reglamento para su ejecución, siendo significativo destacar la transformación, por incremento, que puede experimentar la zona marítimo-terrestre, como secuela tanto de accesión natural, artículo $2 .^{\circ} \mathrm{de}$ la Ley de Puertos y $5^{\circ}, 1$ y 2 , de la Ley de Costas citadas, cuando dice que «son de dominio público los terrenos que se unen a la zona marítimo-terrestre por las accesiones y aterramientos que ocasione el mar», de modo que "cuando por consecuencia de estas accesiones $y$ por efecto de retirarse el mar la linea interior que limita la expresada zona avance hacia aquél, los terrenos sobrantes de lo que era antigua zona marítimo-terrestre pasarán a ser propiedad del Estado...», y como accesión artificial -arts. 5., 2 y 3, y 18, respectivamente, de las Leyes de Costas y Puertos Deportivos 55/1969, de 26 de abril-, al establecer que «los terrenos ganados al mar como consecuencia de la construcción de un puerto deportivo o de su paseo marítimo de ribera serán propiedad privada de sus concesionarios, sin perjuicio de las servidumbres y limitaciones a que quedaren sometidos de acuerdo con la legislación vigente», principios que tienen su parangón en los artículos 366 y siguientes del Código Civil, al regular, en sus diversas manifestaciones y efectos, la accesión respecto de bienes inmuebles.

CONSIDERANDo: Que lo expuesto es coherente con los principios de rango descriptivo de lo que constituye el mar territorial, tanto en lo que a la columna de agua, lecho, subsuelo y recursos, como al espacio aéreo suprayacente, en cuanto es objeto de tratamiento, de orden político, como espacios determinantes del ejercicio soberano por el Estado español, en la Ley 10/1977, de 4 de enero, sobre mar territorial, consecuencia que nos conduce a la valoración de la base física sobre la que se ha de asentar y asienta, en su esencia fundamental, el puerto deportivo de invernada objeto de concesión, en su construcción y explotación, por los actos administrativos objeto de impugnación y que está representado por los 24.100 metros cuadrados a que se refiere el apartado B) de la Orden concesional, respecto de los cuales, en función de la accesión artificial, se le asigna la propiedad al que la lleva a efecto, de acuerdo con las normas que ya indicábamos $-5 .^{\circ}, 3$, de la Ley de Costas y 18 de la Ley de Puertos Deportivos-, de modo que es preciso establecer, como secuela natural, que ese terreno a ganar al mar constituye la sede física, por accesión artificial de la construcción del puerto, sus instalaciones y urbanización, sin que pueda sustraerse a los principios rectores de la Ley sobre Régimen del Suelo y Ordenación Urbana, en su Texto refundido por Real Decreto 1346/1976, de 9 de abril, y Reglamento de Planeamiento para su desarrollo - Real Decreto 2159/1978, de 23 de junio-, en orden a la precisa y obligada observancia de las disposiciones sobre ordenación urbana, como derivación de lo prevenido en los artículos 57 y 58 de la Ley del Suelo, porque con independencia de las facultades privativas - competencias concurrentes- que la Ley de Puertos Deportivos 55/1969, de 26 de abril, y su Reglamento asignan al "Gobierno, a propuesta del Ministerio de Obras Públicas y Urbanismo, para acordar la construcción y explotación de puertos deportivos...» - art. 9.', 1, Ley 55/1969_, de acuerdo con lo prevenido en dicha Ley y las condiciones técnicas, financieras y deportivas pre- 
cisas, para que sea aconsejable su construcción, no puede olvidarse que las posibilidades de urbanización del terreno adquirido por accesión exige como presupuesto su acomodación a la ordenación urbana vigente, y aplicable al lugar de ubicación del puerto, con el presupuesto previo de la clasificación del suelo, porque otra cosa sería quebrantar, conculcando lo prevenido en los artículos 6., 19, 1, a), y 76, 6, del Reglamento de Planeamiento.

CONSIDERANDO: Que la precisa coordinación de la facultad del "Gobierno para acordar la construcción y explotación de puertos deportivos en las zonas o puntos del litoral en que lo considere conveniente..." no excluye ni elimina la necesidad de observar la ordenación urbana aplicable, porque organizado el Estado «territorialmente en Municipios...» hemos de tener presente lo que se entiende como su territorio; y el artículo 11 de la Ley de Régimen local y 2., 1 , del Reglamento de Población y Demarcación Territorial de las Entidades locales -Decreto de 17 de mayo de 1952- expone que "se entiende por término municipal el territorio a que extiende su jurisdicción un Ayuntamiento", y este territorio, independientemente de las modificaciones - alteraciones- que puede experimentar de acuerdo con los artículos $4 .^{\circ}$ y siguientes del Reglamento arriba citado, es indudable que los que tienen límite al mar territorial, como se ha comprobado, pueden experimentar incrementos por accesión natural o artificial, y si la accesión natural constituye fenómeno físico que puede tener una cierta imprevisibilidad, no así cuando se proyecta con la concurrencia de los medios técnicos actuales, como en el supuesto concreto, en el que con caráter previo y como base esencial de su construcción e instalación se había de ganar al mar territorial 24.100 metros cuadrados, con lo cual se está planeando y proyectando sobre terreno que, prescindiendo de su naturaleza y titularidad, se integra en el ámbito territorial del Municipio, con todas las consecuencias que ello implica, claramente expuestas en las sentencias de 25 de septiembre de 1981 y 3 de diciembre de 1982, que expresan "la necesidad de rechazar todo intento de desapoderar a los Municipios de las competencias urbanísticas en las zonas maritimo-terrestres, playas y zonas portuarias, tanto en punto a la intervención singular por la via de licencia como en punto a la ordenación urbanistica, es decir, en suma se insiste en que la ordenación y la ejecución urbanistica es competencia exclusiva que a los Ayuntamientos corresponde en las precitadas zonas, como en general en el territorio que pertenece a los términos municipales de aquéllos».

CONSIDERANDO: Que, sentado lo anterior, es preciso examinar el aspecto concurrente de competencias, con objeto de delimitar la actuación de las facultades específicas atribuidas por la misma a cada uno de los órganos intervinientes, examinando: de un lado, las previsiones derivadas de los artículos 10,$1 ; 12,1, a)$, y 17, 1, de la Ley del Suelo y Ordenación Urbana, en relación con los artículos 57 y 58 y 178 y 180, 1, de la misma, y los 6.․ 19, 1, a), y 76, 6, del Reglamento de Planeamiento, frente a las previsiones establecidas por el artículo 9. de la Ley especial de Puertos Deportivos 55/ 1969, al disponer que «el Gobierno, a propuesta del Ministerio de Obras Públicas, podrá acordar la construción y explotación de puertos deportivos en las zonas o puntos del litoral en que lo considere conveniente...", cuya reali- 
zación, ejecución o explotación puede llevarse a efecto "por las Corporaciones locales, Consejo Superior de Deportes, clubs náuticos u otros deportivos con actividades náuticas y demás personas jurídicas o naturales de nacionalidad española, y, en su defecto, por el Estado" - art. 5.ं de la Ley y 9.॰ de su Reglamento-; y, de otro, la actuación competente de los órganos cointeresados, interés que, basado en normas de igual rango, es preciso coordinar, en razón del alcance finalista que las inspiran, y, ni aun con la salvedad contenida en la prescripción 2) del apartado B) del acto concesional de 26 de octubre de 1979 se logra, pues da lugar al equívoco de una actuación que, infravalorando la ordenación urbanistica, se soslaye en lo esencial la competencia municipal, a lo que contribuyen los extremos a), b) y c) en que se desarrolla la prescripción antes citada, puesto que la subordina en su aplicación a la concesión propugnada.

ConsIDERANDo: Que si hemos destacado una competencia concurrente, es preciso poner de manifiesto dos aspectos esenciales que marcan y destacan con especial énfasis la singularización de la Ley 55/1969 frente al régimen establecido por la Ley del Suelo: una, de valoración técnico-juridica, que está representada por una doble proyección, la que se manifiesta en la rígida regulación de las características que como mínimas deben reunir tanto los puertos deportivos de invernada o base y de escala, objeto de regulación en los artículos $3 .^{\circ}$ y $4 .^{\circ}$ de la Ley y desarrollados en los $2 .^{\circ}$ al $90^{\circ}$ del Reglamento, así como las previsiones basadas en la cualificación del técnico que ha de proceder a la elaboración del proyecto - Ingeniero de Caminos, Canales y Puertos-, con especificación de los presupuestos exigibles para la ejecución de las obras que han de tener su expresión en la memoria, planos, pliego de prescripciones técnicas particulares, presupuesto, estudio económico y financiero del puerto y reglamento de explotación, conforme se expresa en el artículo 19 del Reglamento de la Ley sobre Puertos Deportivos; y la que es deducible del artículo 9. de la Ley, en cuanto que se faculta al Gobierno, a propuesta del Ministerio de Obras Públicas y Urbanismo, a concretar la ubicación del puerto deportivo en las zonas o puntos del litoral en que lo considere conveniente; $\mathrm{y}$, otra, de orden económico-social, en cuanto a la proyección que, en orden al fomento del turismo - art. 19 Ley 55/1969-, suponen la construcción y explotación de puertos deportivos, tanto de invernada o base como de escala, y la necesidad de que respondan a motivaciones claras no sólo en su rentabilidad, sino de satisfacción social, ecológicas y de atemperación con el entorno y medio ambiente, de modo que constituya elemento integrador en su emplazamiento; ahora bien, todo lo consignado debe llevarse a efecto sin perjuicio de que en "ordenación general se tendrá en cuenta en lo que pudiera afectarle las prescripciones establecidas en las normas de planeamiento urbanístico, aplicable a la zona costera en que se ubique» - art. 10, 1, del Reglamento de Puertos Deportivos-.

Considerando: Que esa proyección, como derivación y consecuencia de lo previsto en el propio ordenamiento específico de Puertos Deportivos, tiene la necesaria correlación en la Ley del Suelo en los preceptos que hemos señalado, con su consecuencia refleja en las sentencias indicadas anteriormente de 25 de septiembre de 1981 y 3 de diciembre de 1982, y en la de 2 de 
octubre de 1967, que establece, iniciando, tal orientación doctrinal, que a su vez se plasma en las de 24 de enero de 1974, 7 de julio de 1978, 17 de marzo y 28 de junio de 1980, señalándose como doctrina la necesidad del efectivo cumplimiento y reconocimiento de la competencia prevalente que en materia de ordenación urbana corresponde a los Ayuntamientos, como derivación de las previsiones contenidas en los artículos 101, 2, a), y 121, c), de la Ley de Régimen local, en conexión con la precisa observancia de las que han sido citadas de la Ley del Suelo en su Texto refundido aprobado por Real Decreto 1346/ 1976, de 9 de abril, en cuanto rectora - art. 10 - «de la ordenación urbanística en todo el territorio nacional" que constituye expresión legitimadora de la intervención y adecuación municipal para el logro de los objetivos urbanísticos con un efecto y eficacia reconocido por la referida Ley a través de un articulado -arts. $39^{\circ}, 60^{\circ}, 7 .^{\circ}, 10,17,31,57$ y 58-, de modo que «ninguna otra disposición de jerarquia normativa suficiente limita la competencia municipal urbanistica, referida tanto a la ordenación como a la ejecución" (sentencia del Tribunal Supremo de 25 de septiembre de 1981), sin que ello implique inmisión de las facultades que son privativas del órgano concurrente en razón a sus especificaciones de carácter técnico, como hemos apuntado y se señala en el artículo 10 de la Ley 28/1969, la de 19 de enero de 1928 y la $55 / 1969$, «en cuanto normas que tienen como objetivo las obras de defensa, saneamiento y ordenación de las costas, playas y puertos, en definitiva, intereses concretos, de sector, que tienen que ajustarse y acoplarse, para su cabal integración, en las previsiones urbanisticas como medio para alcanzar la estabilidad y armonía del todo urbano".

Considerando: Que es hecho notorio la previsión en el Plan General de Ordenación Urbana de Alicante de un puerto deportivo con ubicación distin. ta del que es objeto del planteamiento en esta litis, sin que en la resolución concesional se haga referencia alguna que motive la conveniencia de tal emplazamiento, sin que se admita la conclusión de la estabilización de las situaciones, porque ello implica dejación de competencias que, por su esencia $e$ inmanencia, son irrenunciables, lo que supone la precisión "del discurrir en un marco de respeto a las distintas competencias en el que los intereses públicos encomendados a una y otra Administración se logren haciendo ju. gar técnicas delimitadoras y de coordinación que alcancen en el Plan su expresión dentro de la configuración que actualmente luce en el artículo 57 de la Ley del Suelo" (sentencia del Tribunal Supremo de 25 de septiembre de 1981), sin que se pueda conceptuar la construcción y explotación del puerto deportivo de invernada, objeto de autos, como obra que por razones de urgencia o por el excepcional interés público exijan un tratamiento especial - sentencia del Tribunal Supremo de 3 de diciembre de 1982-, como medio de obviar la prohibición, derivada del artículo 138 de la Ley de Régimen local, del otorgamiento de licencias para construir en terrenos que no tuvieran la condición de solares edificables, sin que previamente se ejecuten las obras que los dote de los indispensables servicios de higiene, seguridad y salubridad, asignándose esa actividad a la propia entidad concesionaria cuando la misma es privativa -art. 101, 2, c), de la Ley de Régimen local-compe- 
tencia de la autoridad municipal -arts. 12 y siguientes de la Ley del Suelo-, sin olvidar la especificación establecida en el artículo 15 de la Ley de Costas, reiterándose, en la sentencia de 24 de enero de 1974, la doctrina mantenida en las de 21 de junio de 1965 y 19 de abril de 1969, que reconocen la competencia de las Corporaciones locales para la concesión de licencias administrativas de obras $e$ instalaciones con los efectos $y$ consecuencias que tales actos comportan en orden a la valoración de que lo que se construye se adecúa a las previsiones urbanisticas, y no se puede sustituir, ni aun indirectamente, como se produce, las atribuciones municipales - sentencias de 24 de enero de 1974 y 28 de junio y 17 de marzo de 1980 citado-, que siguen la orientación doctrinal, acentuándola, ya prevista en las sentencias de 20 de mayo de 1961, 29 de marzo de 1963, 13 y 15 de octubre de 1964, porque son cuestiones distintas las previsiones de carácter técnico exigibles por la legislación típica -Puertos Deportivos- y las características que deben reunir las edificaciones $e$ instalaciones para su conformación a lo planeado como exigencias urbanas del término municipal.

Considerando: Que si hemos apuntado la ausencia de razones motivadoras de "conveniencia», en la designación del lugar de ubicación del "puerto deportivo de invernada" es por las consecuencias de contradicción y desconocimiento que, en orden a las previsiones urbanísticas, se establecen en el Plan de Ordenación de Alicante, que obligaría a la reestructuración del mismo, en todo cuanto concierne a la instalación de servicios y a las exigencias que son de obligado cumplimiento, según el artículo 12 de la Ley del Suelo, lo que implica una clara transgresión de la ordenación urbana objeto de elaboración y subsiguiente aprobación en su momento - sentencias del Tribunal Supremo de 7 de julio de 1978 y 24 de enero de 1974-, destacándose así la imprescindible coordinación entre los órganos que participan, con competencias concurrentes en una materia, sin que la prevalencia de actuación radique en el rango de los intervinientes, sino en la naturaleza de las atribuciones que le han sido conferidas por el Ordenamiento jurídico como derivación de la concepción del "Estado social y democrático de Derecho" que se establece en el artículo $1^{\circ}, 1$, de la Constitución, sin que se pueda olvidar, por otro lado, las consecuencias de repercusión responsable que, en orden a la higiene, seguridad y salubridad de un núcleo urbano ex novo, y al margen de la ordenación del término municipal, se trata de asentar en su territorio, y que conllevan todas aquellas que se le asigna por la Ley, de modo singular las que son objeto de descripción en los artículos 101 y 102 y siguientes de la Ley de Régimen local, circunstancias que nos conducen a la lógica conclusión de estimar el recurso interpuesto por la representación legal del Ayuntamiento de Alicante, contra el acuerdo del Consejo de Ministros de fecha 26 de octubre de 1979, que a propuesta del Ministerio de Obras Públicas y Urbanismo otorgó la construcción y explotación de un puerto deportivo de invernada en el término municipal de Alicante, en el tramo de costa denominado "La Albufereta", confirmada por la desestimación del recurso de reposición dictado en 13 de julio de 1981, acuerdos que anulamos en cuanto estimados que los mismos no están ajustados a Derecho. 
para la autoridad municipal cuando impliquen la denegación de licencia o la imposición de medidas correctoras, según se desprende del artículo $78^{\circ}$, párrafo 2, y Disposición Adicional 4." del Reglamento tantas veces mencionado. (Sentencia de 29 de febrero de 1984, Ar. 1115.)

\section{ACtividades molestas, inSAlubres, NOCIVAS Y PEligrosas: FACULTADES DE La ADMINISTRACIÓN MUNICIPAL}

Habida cuenta de que la sanción que se combate y el apercibimiento de desalojo que la precedía tienen como único fundamento la infracción urbanística que supone la circunstancia de almacenar los repetidos productos sin haberse provisto de la preceptiva licencia y la imposibilidad de concederla, por vía de legalización, por impedir el ordenamiento urbanístico vigente el establecimiento de la correspondiente actividad en el lugar elegido, y si bien es cierto que para conceder tal licencia cuando de actividades calificadas se trata, es necesario incoar el oportuno expediente y provocar la intervención de la Comisión Provincial de Servicios Técnicos, conforme al Reglamento y la Instrucción invocados por la apelante y consignados en los «vistos»-el cual aquí, efectivamente, no se promovió-, no es menos cierto que precisamente, conforme a la expresada normativa, antes de que se admita a trámite por la autoridad municipal cualquier solicitud de licencia para aquéllas o se intente la legalización de las desarrolladas sin ella, es imprescindible que por dicha autoridad, con competencia exclusiva no influenciable por los informes o medidas correctoras que tal Comisión pudiera después emitir o imponer, califique, en concreto, sobre si, conforme al planeamiento urbanistico o a las Ordenanzas municipales que sean de aplicación, el lugar elegido para la instalación o el en que la actividad se venga ejerciendo sin licencia es urbanisticamente idóneo, $y$ es el caso que de las actuaciones practicadas consta, sin prueba alguna de lo contrario, que cuestionada instalación no estaba permitida por citado planeamiento, $y$ por ello ni se podia legalizar el ejercicio de la actividad ni tenía por qué seguirse el invocado procedimiento especial a fin de imponer una sanción que, por otra parte y como va dicho, no era más que la materialización del apercibimiento que precedentemente se habia hecho por el ilegal desarrollo de aquélla. (Sentencia de 16 de marzo de 1984, Ar. 1336.)

\section{Cerramiento de ático: Legalización imposible}

Resulta indiscutiblemente comprobado que el demandante, propietario y ocupante del piso noveno del edificio número 85 de la calle Marqués de Casa Valdés, procedió al cerramiento de un espacio sito en la cubierta del mencionado edificio, en el que no existe otra instalación que la que alberga los aparatos mecánicos para los aparatos elevadores o ascensores, no siendo una construcción provisional, sino fija y cerrada por todos sus lados o factible de serlo que obstaculiza la luz y el soleamiento de las viviendas altas. 
$\mathrm{Y}$, en consecuencia, es imposible su legalización porque, dadas las carac. terísticas de lo hecho, se trata de lo practicado en un edificio fuera de ordenación y a lo que no puede calificarse de pequeña reparación exigida por la higiene, el ornato o la conservación de aquél, y tampoco constituye una obra de consolidación de las que, en casos excepcionales, autoriza el artículo 60 del Texto Refundido de 9 de abril de 1976. (Sentencia de 24 de enero de 1984, Ar. 148.)

\section{Licencias: Pago de la tasa}

El pago del arbitrio de licencia de apertura de establecimiento no presupone ni prejuzga, en manera alguna, la resolución administrativa sobre la licencia de apertura, según consta expresamente establecido en los números 2 y 3 del artículo 2. de la Ordenanza Fiscal número 31, asi como tampoco la autorización otorgada por la Delegación de Industria favorable al traslado $y$ puesta en marcha de la industria prejuzga ni dispensa de la obligatoriedad de obtener el correspondiente permiso municipal en función de las circunstancias urbanísticas concurrentes en la zona. (Sentencia de 12 de marzo de 1984, Ar. 1289.)

\section{LiCENCIA DE AUTO-TAXIS: REVOCACIÓN: COMPETENCIA}

Ante la falta de datos sobre cuál haya sido el órgano que otorgara la licencia de que se trata, lo primero que puede decirse sobre este extremo es que la incompetencia del Alcalde, de existir, no es manifiesta, sino, por el contrario, muy dudosa; que en la Ley de Régimen local no aparece atribución de competencias en este tipo de actos, ni a favor del Ayuntamiento Pleno (art. 121), ni de la Comisión Municipal Permanente (art. 122), mientras que a favor del Alcalde sí que se hace referencia a ello en términos generales $y$ afines (art. 116, e) ), aparte la competencia residual que este mismo artículo 116 le confiere en su apartado i); razones que se conjugan y que permiten declarar la improcedencia de anular el acto, en este proceso residenciado, por este motivo. (Sentencia de 25 de enero de 1984, Ar. 156.)

\section{LICENCIA DE OBRAS: CARÁCTER REGLADO DE LA MISMA}

CoNSIDERANDo: Que en materia de licencias municipales de obra o edificación, la Sala ha declarado con reiteración - sentencias de 13 de diciembre de 1973, 24 de octubre de 1974, 24 de febrero de 1977, 31 de enero de 1980, 3 de febrero de 1982, 27 de mayo de 1983, etc.- que el acto licencia postula inminentemente una obligada adecuación a la norma urbanistica, plan, etc., no sólo como presupuesto existencial, sino incluso de licita vigencia; ello explica el carácter reglado de esta actividad administrativa que impone, en consecuencia, a la autoridad municipal la obligación de resolver el problema planteado dentro de los limites previstos en la normativa urbanistica aplicable al sector de ubicación de la finca, etc., en el momento de decidir en tiempo 
thábil o normal de conformidad con lo establecido en la normativa procedimental, y tal como ha sostenido la doctrina de la Sala - sentencias de 18 de marzo de 1970, 17 de octubre de 1973, 28 de enero de 1974, 29 de septiembre de 1975, 13 de julio de 1983, etc.-, y que culmina con la sentencia en revisión -sentencias de 15 de abril y 29 de septiembre de 1981-. (Sentencia de 10 de enero de 1984, Ar. 126.)

\section{LICENCIA DE OBRAS: CONCEPTO}

El Tribunal Supremo en numerosas sentencias, como las de 19 de junio y 17 de octubre de 1979, tiene declarado que las licencias de construcción constituyen una especie del género más amplio de las autorizaciones, acto administrativo de los que amplían la esfera jurídica de los particulares, sin que, por tanto, suponga el nacimiento ex novo de un derecho, sino que posibilitan el ejercicio de las facultades ínsitas en el derecho de propiedad, por lo que el otorgamiento de la licencia municipal para obras y construcciones en terrenos privados no es un acto discrecional, sino reglado de la Administración, en el que ésta se limita a controlar si tal modalidad de ejercicio de las facultades dominicales del particular se ajusta a las disposiciones que la encauzan y regulan de interés público. (Sentencia de 31 de enero de 1984, Ar. 495.)

\section{LiCENCIA DE OBRAS: DENEGACIÓN}

Son fundamentos para la denegación el no haberse acompañado a la solicitud de licencia el correspondiente Proyecto, sino un simple anteproyecto; el no haberse cursado previamente la solicitud de derribo de las construcciones existentes sobre el solar que se pretende edificar, $y$, en fin, y sobre todo, que se pretende la construcción de una planta más de las que autoriza la Ordenanza, lo cual a todas luces justifica la denegación de la licencia, sin que sea posible reconducirlo a la apreciación de simples defectos subsanables, como se postula por la parte. (Sentencia de 1 de febrero de 1984, Ar. 1015.)

\section{LICENCIA DE OBRAS: DENEGACIÓN INDEBIDA}

TERCERO: Que una segunda motivación de la resolución recurrida consiste en la idea de que "puede ser necesaria la intervención de la Dirección General de Vías Pecuarias", argumento desestimable, pues, conforme a lo antes dicho sobre naturaleza y competencia respecto de la licencia municipal, su concesion se entiende sin perjuicio del derecho de propiedad y dejando a salvo el derecho de terceros, $y$ no requiere una previa justificación documental de carácter absoluto, y asi la creencia de que alguna persona privada o algún sector de la Administración pública pueda ostentar algún derecho de propiedad no es causa válida de denegación del acto solicitado ni es función propia de la licencia municipal la de servir a modo de gestión oficiosa de intereses ajenos, que, en su caso, y por los medios procedentes, podrian ser hechos valer por quien corresponda y ante la jurisdicción que sea procedente. (Sentencia de 24 de mayo de 1984, Ar. 446.) 


\section{LICENCIA DE OBRAS: OBRAS MENORES}

El examen detenido de los diversos supuestos de hecho que nuestra jurisprudencia ha calificado de «obras menores»-sentencias, entre otras, de 23 de enero de 1976, 6 de marzo de 1978, 26 de enero y 2 de febrero de 1979, 19 de mayo y 13 de junio de 1980 y 26 y 28 de mayo de 1981 - permite afirmar que las "obras menores" se caracterizan por ser de sencilla técnica y escasa entidad constructiva y económica, consistiendo normalmente en pequeñas obras de simple reparación, decoración, ornato o cerramiento que no precisan de proyecto firmado por profesionales titulados, ni de presupuesto elevado, $y$ es indudable que tales características no son predicables de unas obras que, como ocurre con las de autos, se someten a la dirección facultativa de dos arquitectos y un aparejador con un presupuesto de 13.407.968,35 pesetas, $y$ que suponen la reforma de un local compuesto de tres plantas mediante la construcción de fábrica de ladrillo y una escalera de unión entre la planta baja y primera que requiere la apertura de un hueco en el forjado del techo de la primera, la instalación totalmente nueva de los servicios de fontanería, electricidad y aire acondicionado y la colocación en la fachada de piezas de granito negro labrado, entre otras obras, y constituye, en definitiva, una reestructuración completa de la distribución de dichas tres plantas con modificación sustancial de elementos estructurales y de la fachada. (Sentencia de 21 de febrero de 1984, Ar. 1083.)

\section{LiCENCIA DE OBRAS: Silencio POSITIVo}

SEgundo: Que desde un punto de vista lógico-jurídico debemos examinar con prioridad la segunda de las cuestiones planteadas, es decir, la operatividad del instituto del silencio positivo, que precisa, de acuerdo con el precepto citado, el 95 de la Ley de Procedimiento Administrativo y el 178, 3, de la Ley sobre Régimen del Suelo y Ordenación Urbana, la concurrencia rigurosa de estos dos requisitos: 1) transcurso de los plazos indicados sin notificación, primero, de la resolución municipal expresa, y después, del acuerdo subrogado de la Comisión Provincial de Urbanismo, y 2) que con la resolución tácita no se vulneren prescripciones de la Ley del Suelo, de los Planes, Proyectos, programas y, en su caso, de las normas complementarias y subsidiarias de Planeamiento, fundada esta exigencia legal en la doctrina jurisprudencial de que no debe concederse por silencio aquello que no es posible de un modo expreso, por su carácter ilegal -sentencias del Tribunal Supremo de 31 de octubre de 1968, 17 de octubre de 1973, etc.-. (Sentencia de 6 de febrero de 1984, Ar. 1030.)

\section{RUINA: DictámENES TÉcnicos}

Refiriéndose la declaración de ruina a la situación de hecho de una edificación, para la apreciación de la misma revisten especial importancia los informes emitidos por técnicos en la materia, enseñando la sentencia de la propia Sala de 27 de septiembre de 1976 que "partiendo de que todo estado de ruina de un inmueble entraña cuestión de hecho cuya resolución ha de 
depender de la valoración de las pruebas aportadas, y ello porque el tema tiene un carácter eminentemente técnico, no cabe duda que dada esta condición, el problema se circunscribe a ponderar y valorar, según las reglas de la sana crítica, los diversos dictámenes adjuntados en el actuado administrativo y en el proceso». (Sentencia de 28 de febrero de 1984, Ar. 1099.)

\section{Ruina: DaÑos Y PERJUICIOS POR DECLARACIÓN ILEGAL DE RUINA Y DEMOLICIÓN}

CoNSIDERANDo: Que frente a la tesis impugnatoria municipal basada en apreciaciones subjetivas generales, el auto de la Sala de instancia de 15 de enero de 1979 ofrece un estudio fundado (documentado y pormenorizado) de la temática discutida, esto es, la determinación de los daños y perjuicios sufridos por los actores-apelados como consecuencia de la actuación ilegal del Ayuntamiento de Madrid (acuerdos de 10 de marzo de 1970 y 28 de julio siguiente), por la que se declaró la ruina inminente de la finca número 28 de la calle de Silva de Madrid, con subsiguiente demolición y desalojo, y tal como se declara por la sentencia del Tribunal Supremo de 19 de mayo de 1976 al decretar la nulidad de tales actos administrativos, a la vez que reconoce a los titulares afectados (comunidad de propietarios y arrendatarios de locales de negocio) el derecho a ser indemnizados por los daños y perjuicios causados por la privación de sus respectivos derechos. Y a tal efecto debe resaltarse que la resolución judicial combatida es acorde con la doctrina de este Tribunal -sentencias de 28 de junio de 1977, 2 de febrero de 1980, 4 de marzo de 1981, 5 de junio de 1981, 14 de diciembre de 1983, etc.-. (Sentencia de 3 de febrero de 1984, Ar. 1021.)

\section{Ruina: OBRas de REPaRAción}

CoNSIDERANDo: Que planteada así la litis, y en la alternativa de decidir si la declaración de ruina de un edificio impide o no la realización de obras sobre reparación del mismo, procede resolverla en el sentido de estimar que ciertamente la declaración de ruina de un edificio, por su propio contenido, se opone o impide la realización de obras que a la reparación del mismo tiendan, a no ser que se trate de obras que sean exigidas por razones de seguridad, que tengan por fin la protección de personas y bienes y que lo sean con el carácter de provisional, que no son precisamente las de autos, pues el instituto de declaración de ruina, en nuestro ordenamiento, a salvo los supuestos de urgencia y de edificios que estén afectados por la normativa urbanistica, no se obtiene sino tras analizar en expediente contradictorio si es o no posible su reparación por medios técnicos normales, y si es o no económicamente aconsejable en función de los gastos que su reparación pueda comportar, y una vez analizadas y resueltas ambas tesis, por virtud de la declaración de ruina, no es dable que sin revisar aquel acuerdo, se opte por da reparación del edificio, pues ello no es sino volver a considerar una cuestión ya resuelta y permitir una actuación que tiende precisamente a dejarla sin efecto, fuera del procedimiento establecido, y también a destruir o alterar la situación que la motivó, con la evidente trascendencia que ello comporta, 
por lo que, en definitiva, hay que estimar que la reparación de un edificio declarado en ruina no sólo es actuación que no puede hacerse sin desconocer esa declaración, esto es, sin respetar su vigencia y efectividad, sino que también tiende a desvirtuarla y dejarla sin efecto, $y$, por tanto, vigente ella no puede válidamente realizarse. (Sentencia de 21 de enero de 1984, Ar. 483.)

\section{PROCEDIMIENTO ADMINISTRATIVO}

\section{Notificación OBLIGAdA a LOS TITULARES DE LICENCIA DE OBRA IMPUGNADA}

La reiterada doctrina de esta Sala proclama la ineludible obligación por parte de la Administración municipal de dar expresamente traslado del escrito denunciando una licencia de obras o edificación a los titulares de la misma, sin cuyo trámite de obligada observancia no es formalmente viable el ejercicio de la pretensión actuada por un administrado en pro de la anulación de una licencia de obras y consiguiente demolición de lo construido al amparo de aquélla, y ello es así, como declara la sentencia de este Tribunal de 1 de abril de 1978, "porque la validez del acto administrativo, presunto o expreso, resultando de la denuncia de una licencia de obras, o de la edificación construida al amparo de ella, requiere que el particular afectado por dicha denuncia pueda ejercitar el derecho a ser oído en el correspondiente expediente administrativo, al concurrir en él la cualidad de interesado establecido en el apartado b) del artículo 23 de la Ley de Procedimiento Administrativo, típica manifestación del llamado principio contradictorio necesario para la prosperabilidad y eficacia de la declaración administrativa que at efecto se produzca, principio que la jurisprudencia ha encarecido reiteradamente por la importancia y trascendencia del mismo, por cuanto de no tenerse en cuenta dicho principio podrian llegar a formularse actos administrativos que lesionaran gravemente los intereses de los administrados, sin que éstos hubieran tenido opción a ni tan siquiera manifestarse al respectow. (Sentencia de 25 de enero de 1984, Ar. 157.)

\section{PUERTOS DEPORTIVOS}

\section{FALTA DE COMPETENCIA MUNICIPAL}

Aquí debe recalcarse que se trata de obras de construcción de un puerto sobre el mar litoral (terrenos ganados al mar) y en tal ámbito es sostenible la competencia exclusiva del Estado, tanto por razón de la situación o ubicación de la obra (sobre franja del mar territorial), como por la naturaleza o carácter de ésta, ya que la Corporación local carece de competencias específicas sobre la materia (Ley de Costas), Ley de 26 de abril de 1969 de Puertos Deportivos y Reglamento de 26 de septiembre de 1980, en cuanto que en la legislación especial (Ley de Costas y de Puertos) sólo se le atribuye compe- 
đencia en el número 4 del artículo 11 de la Ley 28/1969, de 26 de abril, para "la gestión y tutela de los bienes de dominio público maritimo terrestre que determine el Gobierno a efectos del fomento de la pescan, y las de policia de moralidad, salubridad, etc., en las playas, salvamento y seguridad (siguiendo las instrucciones generales del Ministerio de Marina, etc.) $e$ instalaciones no fijas y explotación de servicios anejos, etc. (art. 17) en las playas o lugares de baño, etc. Debiendo destacarse que tanto la Ley de Puertos Deportivos como su Reglamento no atribuyen competencia alguna a los Ayuntamientos (al margen de la competencia urbanística sobre accesos o elementos complementarios a los que luego se aludirá), sin perjuicio de prever la posibilidad de que las Corporaciones puedan o deban ser concesionarios (dedicando a tal supuesto el Reglamento los arts. 17 y sigs., cap. $3^{\circ}$ ) en esta materia, y que asimismo tal competencia limitada y subordinada al Estado se aprecia en los artículos 15, 16, 17 y 26 respecto de la competencia local en puertos de interés local, en la Ley de Puertos de 1928. Y todo ello sin ignorar que hoy la competencia en materia de puertos deportivos corresponde a la correspondiente Comunidad Autónoma, por aplicación del artículo 148, 6, de la Constitución, y que también prevé el artículo 31, número 15, del Estatuto de la Comunidad Valenciana - Ley Orgánica 5/1982, de 1 de julio-.

CONSIDERANDO: Que por ello el requisito de la exigibilidad de la licencia municipal de obra sólo es referible en relación con la actividad urbanística $y$ de edificación, a que se refiere el artículo 178 de la Ley del Suelo. Y desde tal perspectiva nadie discute la competencia municipal, y la propia concesión la reconoce en la cláusula 16 , que ha de relacionarse con las prescripciones contenidas en la cláusula 24 y concordantes al imponer la redacción de un proyecto complementario y sucesivo de obras (redes de servicios básicos, accesos por tierra y conexiones, etc.), en que será precisa la autorización municipal, como ya declaraba en su resolución la Dirección General de Puertos, pero referida a una fase posterior de las obras a realizar en suelo comprendido dentro del término municipal y que por accesión comprende o engloba a los ganados al mar (como consecuencia de las obras que autoriza la concesión), porque propiamente es o resulta difícilmente encuadrable entre los supuestos previstos en el artículo citado de la Ley del Suelo y el artícuto $1 .^{\circ}$ del Reglamento de Disciplina Urbanística la construcción de un puerto sobre el mar litoral, desbordando, objetivamente, las operaciones de vaciado, conforme al proyecto de obra, de materiales, etc., en el mar territorial la operación de movimiento de tierras, a que se refiere el artículo 178 de la Ley del Suelo. (Sentencia de 20 de febrero de 1984, Ar. 1078.)

\section{SERVICIOS}

\section{TRANSPORTE COLECTIVO URBANO: COMPETENCIA MUNICIPAL}

Siendo el transporte colectivo de superficie de viajeros por vías urbanas de exclusiva competencia municipal, es el Ayuntamiento el representante de los intereses de los potenciales usuarios del servicio público de transporte, esto es, de los residentes en la capital, así como de los transeúntes, argu- 
mento ya por sí suficiente para desestimar la pretendida causa de inadmisibilidad, que se opone prescindiendo de que, según los artículos 59 y 101 . ambos de la Ley de Régimen local, corresponden al Alcalde o al Ayuntamiento, y, por tanto, son de su competencia el gobierno y la administración de los. intereses peculiares de los pueblos, y no puede dudarse que afecta a esos. intereses generales el mantenimiento o elevación de un servicio público tan esencial en un Municipio como el de transporte colectivo urbano. (Sentencia de 21 de enero de 1984, Ar. 188.)

\section{URBANISMO}

\section{DEMOLICIÓN DE CONSTRUCCIONES SIN LICENCIA}

CONSIDERANDO: Que no es óbice a la demolición acordada que la construcción de que se trata se hubiera levantado hacía catorce años al momento de incoarse el expediente, ya que la normativa jurídica contenida en el citado artículo 171 de la Ley del Suelo de 12 de mayo de 1956, equivalente, según se dice, al artículo 185 del Texto Refundido de la Ley sobre el Régimen Jurídico de Ordenación del Suelo, no fija plazo alguno de caducidad para la actuación de medidas de "demolición" o «legalización», siendo la acción de denuncia de infracciones urbanísticas de carácter público, principalmente en las construcciones clandestinas - que por definición legal son las realizadas sin la oportuna licencia municipal-; congruente con lo cual el artículo 188 del Texto Refundido establece que los actos de edificación o uso del suelo relacionados en el artículo 178 que se realicen sin licencia u orden de ejecución sobre terrenos edificados en el planeamiento como zonas verdes o espacios libres, quedarán sujetos al régimen previsto en el articulo 185 cuando se hubieren consumado, sin que tenga aplicación la limitación de plazo que establece dicho artículo. (Sentencia de 13 de marzo de 1984, Ar. 1751.)

\section{URBANIZACIONES PRIVADAS}

SEgundo: Que los Planes Parciales que tengan por objeto urbanizaciones de iniciativa privada, comportan para los promotores una serie de obligaciones derivadas de los compromisos que se hubieren contraido con el Ayuntamiento, conforme determina el artículo $41,2, d$ ), de la Ley del Suelo de 1956 -56 del Texto Refundido de 1976-, entre las que se encuentra el cumplimiento del plazo de ejecución de las obras de urbanización -artículo 46, b), 1., del Reglamento de Planeamiento-; debiendo destacarse, por otra parte, que los enlaces con el sistema general de comunicaciones constituye una de las determinaciones de los Planes Parciales (art. 13, 2, b) ). (Sentencia de 3 de febrero de 1984, Ar. 1026.)

\section{Planes de Reforma Interior}

Los Planes Especiales de Reforma Interior no previstos en el Plan Generat pueden modificar el uso del suelo urbano establecido en este Plan General; 
sin necesidad de una previa o simultánea revisión del mismo por no venir integrada la calificación de ese uso dentro de su estructura fundamental. (Sentencia de 21 de marzo de 1984, Ar. 1393.)

\section{Planes: Competencia de los Ingenieros Industriales}

CONSIDERANDo: Que haciendo aplicación de la doctrina anteriormente expuesta a la cuestión de recurso, hay que reconocer a los Ingenieros Industriales Técnicos Superiores competencia, al menos, para la redacción de aqueIlos Proyectos que no suponen ordenación integral de un territorio, cualquiera que fuere el nivel de su planeamiento, es decir, sea éste de ámbito nacional, supraprovincial, provincial, comarcal o municipal, toda vez que en su Plan de Estudios - al menos, cuando fue promulgado el Decreto de 18 de septiembre de 1935- no figuraban materias relativas a la ciencia del urbanismo; pero, a no dudar, hay que reconocerle esa competencia -llenando así, siquiera sea en forma incompleta, un vacio legislativo-, para la redacción de aquellos otros Proyectos de alcance más limitado y enteramente subordinados a las directrices y determinaciones propias de los Planes de Ordenación primeramente citados, como ocurre con los Planes Parciales, Proyectos de Urbanización, Programas de Actuación y Estudios de Detalle, pues al tener éstos que ajustarse, a virtud de lo dispuesto en los artículos 13, 1; 14, 3, y 15, 3, a las directrices y determinaciones de los Planes Generales, que no pueden ni alterar ni modificar, hay que admitir la capacitación de ellos para la formación de citados Proyectos. (Sentencia de 16 de marzo de 1984, Ar. 1335.)

\section{Planes de Ordenación Urbana: Aprobación}

Habida cuenta de la doctrina urbanística al uso, en la aprobación de los Planes de Ordenación Urbana no existe en realidad auna función fiscalizadora o de tutela", sino más bien "una aplicación de la técnica de las competencias compartidas", lo que permite en el momento de su aprobacion definitiva, el examen total del Proyecto del Plan en cuestión en todos sus aspectos, pudiendo tomar, en consecuencia, la resolución más adecuada con lo que de dicho examen resulte, como dispone el artículo $132,3, b$ ), del Reglamento de Planeamiento. (Sentencia de 6 de febrero de 1984, Ar. 1029.)

\section{SUELO URBANIZABLE}

SEgundo: Que el Proyecto de delimitación del suelo urbano que, a tenor del artículo 81 de la Ley del Suelo, sirve en los Municipios carentes de Plan para distinguir aquel suclo del no urbanizable, se apoya en una operación de constatación de que los terrenos que abarca tienen edificación consolidada en la mitad, por lo menos, de su superficie, o bien de que cuentan con los servicios que aquel precepto señala, operación de constatación que lleva, además, consigo una correlativa valoración técnica, puesto que la Administración ha de considerar suficientes a su fin los citados servicios y la edificación, 
consolidada y en el porcentaje indicado. (Sentencia de 22 de febrero de 1984, Ar. 1087.)

\section{APROVECHAMIENTO MEDIO DEL SUELO}

Considerando: Que el que tenga una trascendencia decisiva en esta cuestión la clasificación del suelo obedece al hecho de que la figura del "aprovechamiento medio", como técnica al servicio de la mejor distribución de beneficios y cargas, entre los afectados por las actuaciones urbanisticas, sea una creación de la Ley reformadora de la del Suelo, de 2 de mayo de 1975, recogida en el vigente Texto Refundido de 9 de abril de 1976, y que en estos textos legales sólo se ponga en juego dicha técnica respecto del "suelo urbanizable programado" (art. 84 del Texto Refundido), pero no respecto del suelo. urbano (art. 83 de dicho Texto). (Sentencia de 30 de enero de 1984, Ar. 224.)

\section{Proyecto de URbanización: Ingenieros Industriales}

Considerando: Que el tema de quienes son facultativos idóneos para intervenir en el planeamiento urbanístico ha sido ya resuelto por esta Sala, que ha producido en esta materia la doctrina, recogida, entre otras, en las sentencias de 2 de abril y 28 de junio de 1982, según la cual la frase genérica de "facultativos competentes con título oficial", que emplean los artículos 24,3 , de la Ley del Suelo de 1956; 31, 2, del Texto Refundido de 1976, y 123, 4, del Reglamento de Planeamiento de 1978, revela el designio legal de no vincular el monopolio de dicha competencia a alguna predeterminada profesión, sino la de dejar abierta la entrada a todo titulo facultativo que ampare un nivet de conocimientos urbanisticos que se corresponda con la clase y categoria de los proyectos que suscriba su poseedor, habiendo declarado la primera de dichas sentencias, cuya más extensa fundamentación jurídica se tiene aquí por reproducida, que el título de Ingeniero Industrial Superior es apto para autorizar un Estudio de Detalle y la segunda reconoce la misma aptitud respecto a Proyecto de Urbanización. (Sentencia de 29 de febrero de 1984, Aranzadi 1107.)

\section{VIVIENDAS}

\section{ADSCRITAS A CENTRO ESCOLAR: DESAFECTACIÓN}

Siendo las viviendas origen remoto de este proceso, bienes afectos a un servicio público, al estar destinadas al cumplimiento de un fin de interés público, carácter que tiene el hecho de proporcionar casa-habitación a los profesores del centro escolar de la localidad en que aquéllas están sitas, para dedicarlas el Ayuntamiento a otros fines, como es el atribuir su uso a particulares, es preciso que se produzca un acto de desafectación, de descalificación de la cosa como de servicio público. (Sentencia de 20 de febrero de 1984, Ar. 1071.)

NeMESIO RODRÍGUEZ MORO 